\title{
EAl Endorsed Transactions

\section{A Review of the Opportunity to Connect Elderly Citizens to the Internet of Things (IoT) and Gaps in the Service Level Agreement (SLA) Provisioning Process}

\author{
C. Peoples ${ }^{1, *}$, A. Moore ${ }^{1}$ and M. Zoualfaghari ${ }^{2}$ \\ ${ }^{1}$ Ulster University, Shore Road, Newtownabbey, Northern Ireland, BT37 0QB \\ ${ }^{2}$ BT, Adastral Park, Martlesham Heath, Ipswich, Suffolk, IP5 3RE
}

\section{Abstract}

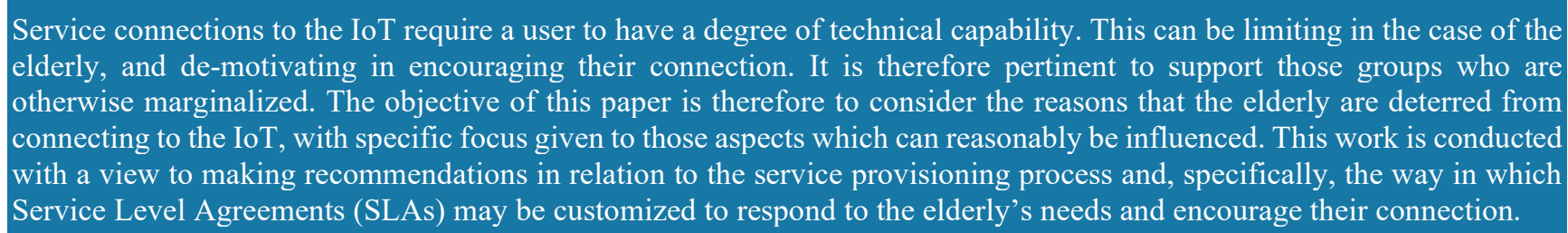

Keywords: elderly citizens, Internet-of-Things (IoT), accessibility, inclusivity, service provision, Service Level Agreements (SLAs), Quality of Experience (QoE).

Received on 31 May 2020, accepted on 26 July 2020, published on 13 August 2020

Copyright (C) 2020 C. Peoples et al., licensed to EAI. This is an open access article distributed under the terms of the Creative Commons Attribution license, which permits unlimited use, distribution and reproduction in any medium so long as the original work is properly cited.

doi: 10.4108/eai.22-5-2020.165993

\section{Introduction}

While the evidence suggests that interest in internet technologies is growing from the perspective of our elderly population, a large gap in the market remains, given that, "After 50 there is a sharp decline in Internet use ..." [1]. By May 2019, only $47 \%$ of adults aged 75 years and over in Britain are recent (having used the internet within the last three months) users [2]. Ofcom, the regulator of broadcasting, telecommunication and postal industries, also reported in May 2019 in relation to the over 75 year old population that, " $48 \%$ do not use the internet" [3]. There therefore exists a significant body of people who can potentially be targeted in any attempt to extend the reach of online technology and services.

"Corresponding author. Email: c.peoples@ulster.ac.uk
The European Commission, which is responsible for bringing forward proposals to support EU laws, describes a smart city as, among a range of other characteristics, one, "meeting the needs of an ageing population" [4]. If a need is therefore identified that elderly users wish to embrace internet technology, but, for some reason or other they are unable to, then the smart city concept is not being fulfilled in relation to the Commission's definition. Taking into account the proportion of older users who are not online today, the objective of this paper is to examine the extent to which older users wish to use online technologies, the reasons that they currently do not, and the interventions which might help to close this gap.

This research is driven by an understanding that trends in technology use by the over $75 \mathrm{~s}$ is changing, which indicates that there may be greater desire to use technology than the statistics on current usage describe: In 2001, 81\% 
of people who said they would definitely not go online were aged over 50 years old; $56 \%$ of these were aged 65 years and over [5]. In 2018, by way of contrast, up to $6 \%$ of people aged 75 and over were living in mobile-only households. Furthermore, by January 2019, one in five people aged 75 and over were using a smartphone [29]. (A study in 2017 reports that $31 \%$ of 75 to 79 year olds and $17 \%$ of those aged 80 and older own smartphones, [21].) These statistics provide evidence that the generation gap is narrowing and suggest that older users may wish to use internet technology to a greater extent than they currently do. Importantly, the number of people aged 65 and over is predicted to increase by $40 \%$ over the next 20 years, and the number of households with a resident aged 85 and over is increasing faster than any other age group [36]. This evidence may therefore highlight a possible gap in the smart city concept from the perspective of the European Commission discussed above. It additionally represents an opportunity which may be exploited by Service Providers, in that, "At $54 \%$ in 2019, this was the first time that over half of adults aged 65 years and over [in the UK] were online shoppers" [28]. However, "While broadband ownership has increased in the last few years, it remains significantly behind that of other age groups - just under half of older (75+) consumers do not have home broadband" [29]. Therefore, while some early evidence suggests that the generation gap is narrowing, there continues to be an uptake gap in comparison to other age groups, and there is an opportunity to contribute to closing it.

In one step towards achieving this, it is necessary to understand the reasons why it exists. It may be the case that internet use is spreading because the elderly today are those who used the internet when they were younger, and skills gained in earlier life shows evidence of persisting in later years. With this assumption, it could be the case that internet use will slowly spread throughout the older population, as the younger generations of today begin to age. Fox predicted in 2001 that the 50-64 age group at that time were the most likely to continue to use the internet after retirement, and that a "silver tsunami" situation would happen [5].

However, this has not come to pass [6]: A study by Age UK in 2016 found that people can have a propensity to give up using the internet as they get older [8]. The study captures activity in relation to internet use within the last 3 months or longer, in which case the user is considered to be an infrequent user or one who has given up using technology entirely. This can occur due to the impacts of change in health, social connections, disposable finance, or simply desire. This finding is also identified by the Oxford Internet Institute (OII) who, in September 2019, describe that the phenomenon of older citizens losing interest in online technologies has persisted since the OII's study began in 2005 [7]. The reason for a lack of use by the older population is therefore not simply due to the fact that they grew up without the internet [9].

It is important to identify the reasons for this trend in behavior, so that solutions can be provisioned to meet the needs of older users. In an attempt to explain the reasons why older users increasingly give up using technology as they age, a UK Governmental study explains that older users have less capacity to retain technological skills [11]. As the ability to operate technology becomes more difficult over time, the evidence suggests that older users step away. They study goes on to describe that, " $60 \%$ of non-internet users aged over 64 consider the internet "too difficult to use,"' [11], verifying that the older population finds online technology prohibitively complex. It is anticipated that this will become an increasing problem in the future, as the breadth of technologies expand, unless specific effort is given to responding to the operational challenges experienced by certain demographic groups.

There is subsequently an opportunity to exploit the fact that more elderly users are online than ever before, but that there continues to be a large proportion who are not. There is therefore potential to work towards minimizing the extent to which some elderly users step away from technology over time.

Different perspectives can be examined to influence the achievement of this. One is to identify if the applications and online services respond to the needs of elderly users. If there are few services online which will attract the older population, there is little incentive for them to participate. Assessing interest in online technologies, however, is difficult, given the evidence of a lack of understanding of what the internet involves [17]. From another perspective, the ease of accessing a service could be examined, given that there are a myriad of ways in which services may be offered to customers; each provider offers their services according to a bespoke set of metrics. A lack of standardization in the ways which services are offered to customers reduces transparency of the provisioning process, and can lead to confusion in how to access them, as verified by Pearson (2019), who states that, "device registration processes are, more often than not, incompatible with humans" [10]. It could be assumed that this becomes increasingly true with age, in line with the findings in [11].

The objective of this paper is therefore to examine the extent to which the elderly population engages with online activities and their barriers to using technology, with a view to understanding if interventions are needed, how they might be put in place, and the impact they could potentially have. In our prior work, an ontology has been proposed with a view to standardizing the information used during device registration and service setup processes. The overall goal is to minimize the input required from customers and, as a result, the need to interact directly with a Service Provider. Enabling this facility is believed to be particularly relevant in the case of the elderly users.

The remainder of the paper is organized as follows. In Section 2, a literature review is presented which examines the extent to which the elderly participate online and the services which are available for them. This is followed in Section 3 with a consideration of the variety of reasons that the elderly are not online. In Section 4, achieving Quality of Experience from the perspective of an elderly citizen is considered, and the drivers for inclusivity are presented in Section 5. The paper concludes and discusses future work in Section 6. 


\section{Literature Review}

A number of literature sources regarding the elderly and IoT technology report on its use to support independent living in the home. The authors of [16], for example, propose a platform to support interoperability between a range of smart devices. The HABITAT project - Home Assistance based on the Internet of Things for the Autonomy of Everybody - aims to support elderly citizens living in their own homes and care homes. As another example, the authors of [14] describe a "watch-over system". This involves motion and temperature-humidity sensors being deployed around the house for the purpose of, for example, alerting when a person has not moved for a pre-defined period and the room temperature exceeding a threshold, or a person has not moved from the bath for a threshold period of time. The system operates only when a person is alone in their home, and ceases operation when others arrive. This system is very specific to the home scenario, and is unlikely to be adaptable to other situations.

Moving closer to exploiting the capabilities of IoT technology, the creation of "elderly-friendly cities" [12] was explored as part of the City4Age project [13], which concluded in early 2019. Proposals made in this project include strategies to collect and manage data about the elderly's activities, with a goal of creating a more supportive city environment. It was proposed through this project to collect data representing behavior patterns, which would then be analyzed to identify novel activity and detect risk. Data was collected using wearable wrist devices and smartphones on User motility, Indoor/Outdoor localization, User/Environment interaction, and Ambient parameters. There is less detail given in [12] on decisions made using the collected context, and the way in which it makes the cities more supportive, and more detail is given on the system architecture which supports smart city operations.

Despite the range of solutions available, however, they do not respond to the service connection needs of older users. To the best of our knowledge, there is little evidence of research or strategy put specifically in place to respond to the elderly's service provision needs. We therefore believe that this is a significant part of the reason which explains why the elderly are not online.

\section{Why are the elderly not online?}

One objective of this paper is to understand the reasons that the elderly do not engage with technology to the extent that other age groups do, and to appreciate the reasons why some elderly citizens use the internet infrequently, or give up altogether.

It has been described, not specifically in relation to elderly users but citizens in general, that, "Most non-users are not interested in going online - they are non-users by choice" [1]. Non-users are most commonly those who are older: It was described in 2015 that, "Almost 30\% of people aged 65-74 [in the UK] have never been online" [17]. This statistic increases as respondents age, with the survey going on to describe that " $61 \%$ of over 75 s have never used the internet" [17]. By 2018, the Office for National Statistics (ONS) reports that $8.4 \%$ of the UK population have never been online [18], and by 2019, this value declines to $7.5 \%$ [2]. More than half of the population who has never been online (4 million) is aged 75 years and older ( 2.5 million) [2]. While this may be because they are not aware what they are missing out on, it is certainly also the case that efforts have not been successful in encouraging them to participate, or in facilitating them in doing so. These are significant figures: 11.9 million people in the UK are aged 65 years and over. 3.2 million are aged 80 years and over, and 1.6 million are aged 85 years and over [36].

"The propensity to explore online decreases with age" [3]. A survey in 2017 by The Local Sweden describes that, "Those who don't use the internet are the very oldest who have made an active choice" [15]. It may be naïve, however, to assume that the older population has actively chosen to not go online: A study carried out in 2015 by BritainThinks on behalf of Age UK describes that, when surveying the elderly population, “... understanding of the internet was low, both in terms of how to navigate it and the commonlyknown range of opportunities that it provides to users" [17]. If they have made a choice to not use it, the evidence suggests that this decision is being made based on imperfect information. Some survey respondents have indicated that they are perhaps unfamiliar with what it means to use the internet: One participant of the study described that, "I would have to sit down and think 'what would I do with this computer?'" [17], reinforcing a lack of familiarity with what is achievable online.

It is, however, not necessarily due to a lack in desire that the older population is not online: The BritainThinks report conveys that older citizens accept that online services are accessible only via friends and family. This indicates that services which respond to the needs of older users are available, and that other barriers between the user and the service exist. A selection of these are considered in more detail in the following sections.

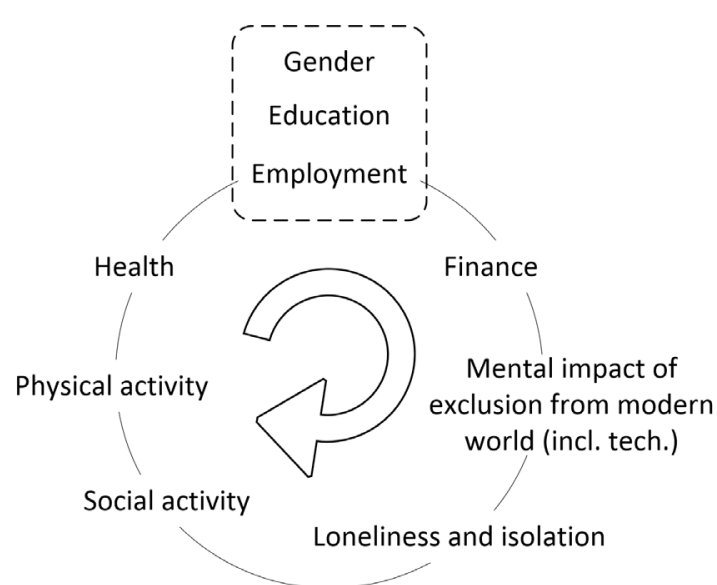

Figure 1. Cycle of Factors influencing Technology Use by the Elderly 


\section{Gender}

Gender is a potential barrier to technology, given the distinction between the number of men and women who are online [2]. Women, in general, use the internet less than men, with $82 \%$ of women across Europe compared with $84 \%$ of men in 2018 [19]. This finding is significant, given that, by 2018 , there were $32 \%$ more women than men in the EU [19]; in relation to the over $65 \mathrm{~s}, 55 \%$ are women [23]. Related to this is the fact that women have a higher life expectancy than men, living on average 5.2 years longer in 2017 [24].

\section{Education}

Education is a significant contributor to online activity "...sorting those who do from those who do not go online" [1] [5] - with educated citizens more likely to be online [21]. In the below 64 years old age group, a higher proportion of women are educated to higher education level than men [19]. This should therefore indicate that there will be more women online than men. As we move into the higher age bracket, however, it becomes more difficult to obtain statistics on education levels and internet use in general, and certainly on a gender-specific basis. Based on trends in internet use and gender, and the influence of education on being online, we might assume that older females are educated to lower levels than men. As the below 64 years old age group continues to age, however, it might be reasonable to assume that the older population who will potentially be online will be female.

Online behavior and activity also varies dependent on education: In $2018,81 \%$ of users with higher educational achievement watched streamed TV and videos in comparison to $66 \%$ who had achieved at most secondary level education [20]. Similar distinctions were observed for those reading news online, with $85 \%$ of users with further education and $56 \%$ with a secondary level of education [20]. We can therefore anticipate a higher frequency of operations made by educated users, in addition to requests requiring a higher volume of bandwidth. Awareness of this activity is important, from the perspective of service providers, through gaining an understanding of the types of capabilities that services should be provisioned for.

\section{Employment}

The employment rate also varies dependent on gender, and this may have a significant impact on who is online. In 2018 in the EU, 74\% of men were employed in comparison to $63 \%$ of women [19]. Those who are employed are more likely to be online than those who are not. However, a significant rise in the number of women who work has been seen for the 50-64 year old age group, rising from 55\% in 2000 to $70 \%$ in 2019 [36]. We might assume that employment will impact the accessibility of online services, with an assumption that those who are employed will be educated, and the correlation observed between being educated and being online. This is useful from the service provisioning perspective, helping to understand the types of services which will be demanded and the volumes of resources required.

\section{Finance}

Closely related to employment is disposable finance, which influences the extent to which users can be online through their ability to buy devices and connect to services [22] [21]. In 2019, the over 80s in the UK are described as being more likely to live in poverty than other age group; furthermore, $16 \%$ of people aged over 65 live in relative poverty [36]. It is therefore reasonable to assume that this demographic will be less likely to be online from a financial point of view. This is also useful knowledge from a service provider perspective, reinforcing the availability of disposable income from this population group.

\section{Mental impact of exclusion from modern world}

The evidence suggests that the elderly have negative emotions about the fact that they are not connected with technology. A study by Pew Research Center reports that, " $34 \%$ of older internet users say they have little to no confidence in their ability to use electronic devices to perform online tasks ..." [21]. "41\% of people aged 65 and over in the UK feel out of touch with the pace of modern life" [37]. The survey carried out by BritainThinks is particularly revealing in relation to how the elderly feel about technology and their interaction with it [17]. They feel vulnerable and uncomfortable having to rely on others to facilitate their internet use. "They talked about feeling ... like a 'dinosaur', 'stupid' and 'vulnerable" [17].

\section{Loneliness and Isolation}

Loneliness and isolation are also significant health conditions, in that they can trigger physical and mental reactions. Physical pain, for example, can restrict a person to home, with a subsequent impact on connection with others. In $2018,39.9 \%$ of women and $20.2 \%$ of men aged 65 and over in the EU were living alone [19]. In 2016, there were $39 \%$ single-person households for the elderly population aged 65 and over in the EU [25]. In 2019, 14\% of men were widowed by the age of 65 compared to $35 \%$ of women [36]. Significantly, "There is a growing concern that loneliness could be the next biggest public health crisis" [13]. A large proportion of society report that the television is their main form of company. This is significant - a recent study describes that more than 3.5 hours of television viewing per day can lead to cognitive decline [40]. It is therefore a vicious cycle to break, of employability, finance, health, and loneliness.

\section{Health}

While employment opportunities are now opened up to elderly citizens, the rate at which this can be exploited is influenced by poor health in older age. With increase in life expectancy, citizens are increasingly spending longer time in poor health [27], which in itself can lead to further health concerns. Depression, for example, in older age can be driven by cognitive impairment, physical inactivity, and anxiety [26], all of which can limit the level of engagement with technology. While life expectancy is increasing in general, in the UK however, it is lower in relation to comparable countries [10]. While the specific causes are not known, it is believed to be due to a range of illnesses: The elderly are vulnerable to social isolation and loneliness, which can lead to cognitive decline [11], dementia, 
depression, and heart disease [12]. A study in 2011 describes, "a positive correlation of Internet use to mental well-being of retired older adults ..." [26]. It is therefore important, particularly from a governmental point of view, to consider strategies which can positively impact on the overhead of elderly healthcare cost.

\section{Location}

Internet uptake varies dependent on location. This is somewhat due to roll out of the network infrastructure in a marketable location-led manner. It is also influenced by the fact that citizen demographics vary across locations, with some citizens being more likely than others to use the internet, and therefore driving different levels of demand. In relation to the fact that fewer older people are online, it may be significant that $25 \%$ of people aged over 50 live in rural areas [36], where broadband connections are less prevalent. It may be more difficult for older citizens to benefit from wireless services due to the (perhaps perceived) complexity of establishing a connection from their perspective.

\section{Complexity of technology and the service provisioning process}

From a front-end application perspective, "One in five [UK adults] say they don't use the internet because it's too complicated ..." [29]. Furthermore, Ofcom reports that, "just under four in ten older consumers (75+) ... are confident that they understand the language and terminology used by providers, compared to the $75 \%$ average" [29]. They also reinforce concern about their ability to use any technologies which emerge in the future [11] due to this apparent loss of knowledge and ability. "30\% of ... people aged over 54 would "use new technologies if they were easier to use"" [31].

\section{Accessibility of mobile devices}

A number of studies investigate the usability of touchscreen devices from the perspective of the elderly. In relation to the devices and applications available at the time of publication (2011), the authors of [32] identify that the elderly generally find touchscreens easy to use. The authors of [32] also describe that the software side of systems can be achieved using, "... senior-friendly interfaces through software-level adaptations" [32]. While this might be true in the case of websites and applications developed specifically for the elderly, it is not necessarily the case that there are 'seniorfriendly interfaces' for the breadth of services offered today. This may therefore also be considered to be a limiting factor.

More recent evidence, on the other hand, suggests that the elderly do have challenges in using modern hardware and software. The authors of [33], published in 2015, describe that "... older adults face accessibility problems when using devices equipped with touchscreen" [33]. More recently again, the authors of [34] describe that, "Consistent with prior results, we found that older adults had longer target selection times, generated higher error rates, and encountered a broader range of selection difficulties ..." [34].

\section{Online crime which targets the elderly}

Feeling out-of-touch with technology can be further amplified by the fact that many become victims when online. A study in 2017 on approximately 42,000 citizens across America concluded that approximately 1 in 18 older adults with full cognitive capacity are victims of financial fraud and scams [38]. This figure could be much larger, with an estimation that only $5 \%$ of scams are reported [39].

In conclusion, some of these barriers to technology uptake, such as gender, cannot be overcome. Furthermore, the role played by gender on subsequent education and later employment might prove to be a longer-term problem to solve (Figure 1). Contributions can be made, however, towards others. Available finance can be impacted either directly, through employment, or indirectly, through reduced cost of devices and/or services. In doing this, the subsequent reactions can also benefit, such as improved social activity, improved health, and so on.

\section{Quality of Experience (QoE) for elderly users}

Quality of Experience (QoE) is commonly referred to in relation to telecommunication services as the satisfaction which a user receives. It is typically an estimate of how satisfied a user is with the latency they are exposed to when operating an online system, or the impact of the achievable data rate on the quality of their application transmission. However, we additionally suggest that QoE is impacted by more social factors, which might be considered to include the finance required to support a service. To this end, it is suggested that by influencing the finance required, this can improve QoE and subsequently heighten service value through positive impact on social and physical activity, and health. We therefore suggest that 'Finance' in Figure 1 is replaced with 'Value' (Figure 2). In addition, 'Gender/Education/Employment', the factors believed to influence the extent to which citizens participate in online services, are replaced with 'Engagement'. By increasing the value of a service, which we position as arising from reduced cost in the case of elderly citizens, we anticipate subsequent positive consequences on feelings of inclusion in society, loneliness, social and physical activity, health, and engagement in life.

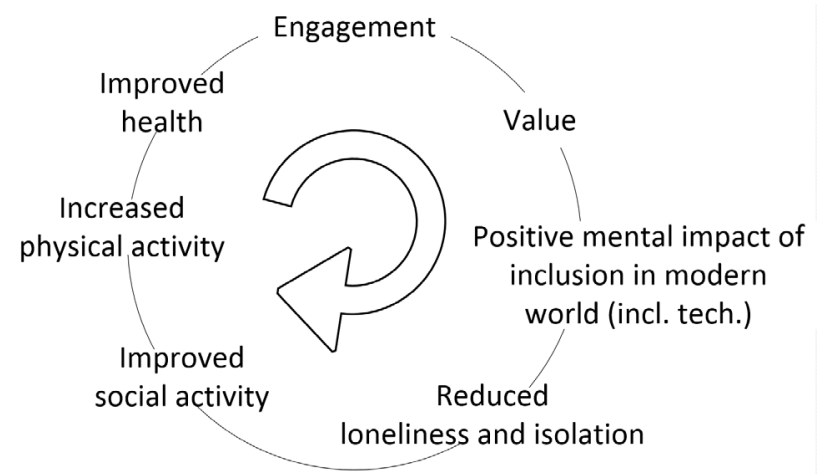

Figure 2. Factors Impacting the Elderly in Technology Use 


\section{Why is improving inclusivity important?}

Inclusivity of the elderly in general is gaining increasing traction, and is promoted by different organizations. The Chatty Café Scheme [48], for example, is supported by Costa Coffee [49] and Cadbury is donating money to Age UK in recognition of just how isolated some are [50] [51].

IoT and the elderly is a research topic which is currently under investigation. However, when we consider technology, or the IoT, and the elderly, a number of the solutions involve its use to support independent living, as in [43] to [46]. There is, however, potential for the elderly to use IoT technology in alternate ways to improve their quality of life. State-of-the-art in technology solutions do not consider that the elderly may use technology to support the wider aspects of life, including their social needs.

Being older doesn't mean that users want to rely on others any more than other age groups. For some participants of the survey, “... asking someone else to do something online for them ... generated negative emotions and participants said they worried about being a nuisance or feeling ashamed and embarrassed to ask" [17]. Some older users of the internet accept that they need help with online services. Related to this, however, it is significant to note that when gathering findings to support definition of the Wellbeing Index by Age UK, "higher intensity helping/caring has a negative effect on wellbeing, while lower intensity helping/caring has a positive effect" [47]. Where the user relies on another completely to support their online activity, this may have a potentially negative and damaging impact.

It is for this reason we firmly believe that making these services available and accessible for older users can have a positive longer-term effect. This should be achieved in a manner which supports self-use as much as possible. Where elderly citizens are aware that their activities are being observed and monitored for the positive, we view this as being a part of "higher intensity helping/caring". Empowering elderly citizens to utilize the services themselves, on the other hand, we view as "lower intensity helping/caring".

\section{Conclusions and further work}

Improving online inclusivity of the elderly is difficult, given that there is a general lack of awareness of what they are missing out on, and the positive impacts which can be introduced by being online. Studies have found that there is a lack of awareness and understanding, which leads to misconceptions; some feel that this is an environment that they don't need to belong to. More tangible aspects can also be off-putting, including impact on their safety and privacy, and cost and ease of access.

There is more at risk for those who are not connected than ever before: With increasing prevalence of a cashless society for example, this can leave those who have not integrated technology into their lives in a vulnerable position. Furthermore, governments and businesses are increasingly moving their services online. Anyone who doesn't participate in online services is therefore at risk of being left behind.

SLA negotiation considers aspects which include data rate and platform availability when agreeing on an acceptable service for a customer. Human factors are not commonly considered. In this paper, a number of human factors that specifically relate to the elderly have been discussed, and future work will involve incorporating these into SLAs.

Acknowledgements.

This research is supported by the BTIIC (BT Ireland Innovation Centre) project, funded by BT and Invest Northern Ireland.

\section{References}

[1] G. Blank and W. H. Dutton, "Perceived Threats to Privacy Online: The Internet in Britain," Oxford Internet Survey, Sep. 2019.

[2] Office for National Statistics, "Internet users, UK: 2019," Statistical Bulletin, May 2019.

[3] The Office of Communications (Ofcom), "Adults: Media use and attitudes report 2019," May 2019.

[4] European Commission, "What are smart cities?" Available: https://ec.europa.eu/info/eu-regional-and-urbandevelopment/topics/cities-and-urban-development/cityinitiatives/smart-cities en\#what-are-smart-cities (last accessed: 26/07/20)

[5] S. Fox, "Wired Seniors, A Fervent Few, Inspired by Family Ties," [Online] Pew Research Center, Sep. 2001; Available: https://www.pewresearch.org/internet/2001/09/09/wiredseniors/ (last accessed: 26/07/20).

[6] B. Knowles and V. L. Hanson, "The Wisdom of Older Technology (Non-) Users," Communications of the ACM, Mar. 2018, Vol. 61, No. 3, pp. 72-77.

[7] M. Ward, "Almost one-fifth of Britons 'do not use internet'," BBC News, Sep. 2019: Available: https://www.bbc.co.uk/news/technology-49607061 (last accessed: 26/07/20).

[8] Age UK, "The Internet and Older People in the UK-Key Statistics," Jul. 2016.

[9] M. Ward, "Almost One-fifth of Britons 'do not use internet'," [Online] BBC News, Sep. 2019; Available: https://www.bbc.co.uk/news/technology-49607061 (last accessed: 26/07/20).

[10] I. Pearson, "IoT Design: An Approach to Design Resilient, Robust, Reliable and Secure Systems," [Online] Farnell, Feb. 2019; Available: https://uk.farnell.com/approach-todesign-secure-and-robust-iot-systems\# (last accessed: 26/07/20).

[11] UK Government Office for Science, "Future of an Ageing Population," [Online] Jul. 20169; Available: https://www.gov.uk/government/publications/future-of-anageing-population (last accessed: 26/07/20).

[12] R. Mulero, A. Almeida, G. Azkune, P. Abril-Jiménez, M. T. Arredondo Waldmeyer, M. P. Castrillo, L. Patrono, P. Rametta, I. Sergi, "An IoT-Aware Approach for Elderlyfriendly Cities," IEEE Access, Vol. 6, Jan. 2018, pp. 79417957. 
[13] CITY4AGE Homepage; Available: http://www.city4ageproject.eu/ (last accessed: 26/07/20).

[14] H. Suzuki, Y. Kiyonobu, T. Mogi, K. Matsushita, M. Hanada, R. Suzuki, and N. Niijima, "An Updated Watchover System using an IoT Device for Elderly People Living by Themselves," in Proc. of $3^{\text {rd }}$ Int. Conf. on System Reliability and Safety, Nov. 2018, pp. 115-119.

[15] The Local Sweden, "Young People in Sweden More Likely to Question Information Online," [Online] Oct. 2017 Available: https://www.thelocal.se/20171019/youngpeople-in-sweden-more-likely-to-question-informationonline (last accessed: 26/07/20).

[16] E. Borelli, G. Paolini, and A. Castanzo, "HABITAT: An IoT Solution for Independent Elderly," Sensors, Mar. 2019.

[17] BritainThinks, "Life Offline - What Life is Like for Older People who Don't use the Internet - A Report Prepared by BritainThinks on Behalf of Age UK," [Online] May 2015; Available: https://www.ageuk.org.uk/globalassets/ageuk/documents/reports-and-publications/reports-andbriefings/active-communities/life_offline.pdf

(last accessed: 26/07/20).

[18] Office for National Statistics, "Internet users, UK: 2018," Statistical Bulletin, May 2018.

[19] eurostat, "The Life of Women and Men in Europe, A Statistical Portrait," [Online] 2019 Available: https://ec.europa.eu/eurostat/cache/infographs/womenmen/ index.html?lang=en (last accessed: 26/07/20).

[20] European Commission, "Culture Statistics - Use of ICT for Cultural Purposes," [Online] Jun. 2019; Available: https://ec.europa.eu/eurostat/statisticsexplained/index.php?title=Culture_statistics__use_of_ICT_for_cultural_purposes\#Use_of_the_internet for_cultural_purposes (last accessed: 26/07/20).

[21] M. Anderson and A. Perrin, "Tech Adoption Climbs Among Older Adults," [Online] Pew Research Center, May 2017; Available:

https://www.pewresearch.org/internet/2017/05/17/techadoption-climbs-among-older-adults/ (last accessed: 26/07/20).

[22] W. H. Dutton and G. Blank, "Next Generation Users: The Internet in Britain," [Online] Oxford Internet Surveys, 2011; Available: https://www.oii.ox.ac.uk/archive/downloads/research/oxis/ oxis2011_report.pdf (last accessed: 26/07/20).

[23] Office for National Statistics, "Estimates of the Population for the UK, England and Wales, Scotland and Northern Ireland," [Online] May 2020; Available: https://www.ons.gov.uk/peoplepopulationandcommunity/p opulationandmigration/populationestimates/datasets/popul ationestimatesforukenglandandwalesscotlandandnorthernir eland (last accessed: 26/07/20).

[24] European Commission, "Gender Statistics," [Online] Feb. 2020; Available: https://ec.europa.eu/eurostat/statisticsexplained/index.php/Gender_statistics (last accessed: 26/07/20).

[25] eurostat, "People in the EU - Statistics on Household and Family Structures" [Online] Available: https://ec.europa.eu/eurostat/statisticsexplained/index.php/People_in_the_EU_statistics on household and family structures\#Singleperson_households (last accessed: 26/07/20).

[26] Y. Wang, H. Zhang, T. Feng, and H. Wang, "Does Internet Use Affect Levels of Depression Among Older Adults in China? A Propensity Score Matching Approach," BMC Public Health, 2019.
[27] Office for National Statistics, "Living Longer: How our Population is Changing and Why it Matters," Aug. 2018.

[28] Office for National Statistics, "Internet access - households and individuals, Great Britain: 2019," Statistical Bulletin, Aug. 2019.

[29] The Office of Communications (Ofcom), "Access and Inclusion in 2018: Consumers' Experiences in Communications Markets," [Online] Jan. 2019; Available: https://www.ofcom.org.uk/_data/assets/pdf_file/0018/132 912/Access-and-Inclusion-report-2018.pdf (last accessed: 26/07/20).

[30] NHS, "UK Life Expectancy Drops while other Western Countries Improve," [Online] Aug. 2018; Available: https://www.nhs.uk/news/medical-practice/uk-lifeexpectancy-drops-while-other-western-countries-improve/ (last accessed: 26/07/20).

[31] J. Damant and M. Knapp, "What are the Likely Changes in Society and Technology which will Impact upon the Ability of Older Adults to maintain Social (Extra-familial) Networks of Support Now, in 2025 and in 2040?" Government Office for Science, May 2015.

[32] M. Kobayashi, T. Miura, and T. Ifukube, "Elderly User Evaluation of Mobile Touchscreen Interactions," Sep. 2011,

[33] L. Genaro Motti, N. Vigouroux, and P. Gorce, "Improving Accessibility of Tactile Interaction for Older Users: Lowering Accuracy Requirements to Support Drag-anddrop Interaction," in Proc. of $6^{\text {th }}$ Int. Conf. on Software Development and Technologies for Enhancing Accessibility and Fighting Infoexclusion, Jun. 2015, pp. 366-375.

[34] A. Sultana and K. Moffatt, "Effects of Aging on Small Target Selection with Touch Input," ACM Transactions on Accessible Computing, Vol. 12, No. 1, Feb. 2019.

[35] J. T. Cacioppo and S. Cacioppo, "Older Adults Reporting Social Isolation or Loneliness Show Poorer Cognitive Function 4 Years Later," Evidence-Based Nursing, Mar. 2014.

[36] Centre for Ageing Better, "The State of Ageing in 2019 Adding Life to our Years," [Online] 2019; Available: https://www.ageing-better.org.uk/publications/state-ofageing-2019 (last accessed: 26/07/20).

[37] S. Davidson and R. Rossall, "Age UK Loneliness Evidence Review," [Online] Age UK, Jul. 2015.

[38] D. Burnes, C. R. Henderson, C. Sheppard, R. Zhao, K. Pillemer, and M. S. Lachs, "Prevalence of Financial Fraud and Scams Among Older Adults in the United States: A Systematic Review and Meta-Analysis," American Journal of Public Health, Jul. 2017.

[39] Neighbourhood Watch, "Scams and Older People," [Online] n.d.; Available: https://www.ourwatch.org.uk/crimes-archive/scams-olderpeople/ (last accessed: 26/07/20).

[40] D. Fancourt and A. Steptoe, "Television Viewing and Cognitive Decline in Older Age: Findings from the English Longitudinal Study of Ageing," Nature, Feb. 2019, pp. 1-8.

[41] National Institute on Aging, "Social Isolation, Loneliness in Older People Pose Health Risks," Apr. 2019 [Online] Available: https://www.nia.nih.gov/news/social-isolationloneliness-older-people-pose-health-risks (last accessed: 26/07/20).

[42] Appello, "The Role of Technology in Combating Loneliness and Social Isolation: A Guide for Housing Providers," [Online] 2017; Available: https://www.housinglin.org.uk/_assets/Resources/Housing/ OtherOrganisation/appello-the-role-of-technology-in- 
combating-loneliness-and-social-isolation-amongst-olderpeople_v6.pdf (last accessed: 26/07/20).

[43] S. Kumar Bhoi, S. Kumar Panda, B. Patra, B. Pradhan, P. Priyadarshinee, S. Tripathy, C. Mallick, M. Singh, and P. Mohan Khilar, "FallDS-IoT: A Fall Detection System for Elderly Helathcare based on IoT Data Analytics," in Proc. of International Conference on Information Technology, Dec. 2018, pp. 155-160.

[44] D. Perez, S. Memeti, and S. Pilana, "A Simulation Study of a Smart Living IoT Solution for Remote Elderly Care," in Proc. of $3^{\text {rd }}$ International Conference on Fog and Mobile Edge Computing, Apr. 2018, pp. 227-232.

[45] S. Benedict Kumar, W. Wei Goh, and S. Balakrishnan, "Smart Medicine Reminder Device for the Elderly," in Proc. of $4^{\text {th }}$ International Conference on Advances in Computing, Communications \& Automation, 2018, pp. 1-6.

[46] A. Almedia, A. Fiore, L. Mainetti, R. Mulero, L. Patrono, and P. Rametta, "An IoT-Aware Architecture for Collecting and Managing Data Related to Elderly Behaviour," Wireless Communications and Mobile Computing, Vol. Dec. 2017, pp. 1-17.

[47] ageUK, "A Summary of Age UK's Index of Wellbeing in Later Life," [Online] Feb. 2017.

[48] Whitbread, "Costa Coffee Rolls Out 'Chatty Café' Scheme Nationwide to get the Nation Talking," [Online] Aug. 2018; Available: https://thechattycafescheme.co.uk/ (last accessed: 26/07/20).

[49] O. Petter, "Costa Rolls Out "Chatter and Natter" Tables Nationwide to Combat Loneliness Epidemic," Independent [Online] Aug. 18; Available: https://www.independent.co.uk/life-style/costa-coffeechatter-natter-tables-loneliness-crisis-silent-epidemic-ukcampaign-a8312076.html (last accessed: 26/07/20).

[50] Age UK, "Donate your Words," [Online] n.d.; Available: https://www.ageuk.org.uk/get-involved/volunteer/donateyour-words/ (last accessed: 26/07/20).

[51] Cadbury, "Give More out with 'Donate your Words' Gifts," [Online] n.d.; Available: https://www.cadburygiftsdirect.co.uk/our-productrange/shop-by-brands/donate-your-words.html (last accessed: 26/07/20). 